\title{
LA ACTUACIÓN ÉTICA EN EL EJERCICIO PROFESIONAL DEL CONTADOR Y LA APLICACIÓN DE LA RESPONSABILIDAD SOCIAL EMPRESARIAL
}

\author{
THE ETHICAL ACTION IN THE PROFESSIONAL EXERCISE OF THE ACCOUNTANT \\ AND THE APPLICATION OF CORPORATE SOCIAL RESPONSIBILITY
}

Jorge Humberto Piedra Luna Universidad Técnica de Machala

Machala, El Oro, Ecuador

ORCID: https://orcid.org/0000-0003-0187-8619

Correo electrónico: jhpiedra_est@utmachala.edu.ec

\section{RESUMEN}

Los sucesivos escándalos empresariales han puesto de manifiesto que la formación profesional de los contadores no es suficiente. Las tendencias actuales de la profesión contable están enmarañadas en innumerables casos de fraude y corrupción, no solo en Ecuador, sino en toda la región de Latinoamericana; esto afecta a los usuarios de la información financiera, a saber, a inversionistas, a órganos de control y al propio Estado, los cuales se encuentran interesados en la razonabilidad que presentan los estados financieros para la toma de decisiones adecuadas. La ética profesional es una necesidad que ha prevalecido en el tiempo, constituyéndose en un eje transversal para cada individuo formado con valores y principios sobre los cuales recae su actuación sobre la sociedad. Por tal motivo, el objetivo de este trabajo es determinar la actuación ética en el ejercicio profesional del contador y la aplicación de la responsabilidad social empresarial, mediante la revisión epistemológica para una nueva percepción de la profesión. La metodología aplicada para la consecución del objetivo planteado fue la revisión bibliográfica del enfoque epistemológico que ha determinado al contador como un profesional íntegro, quien antepone los intereses de la empresa antes que los propios, además, actúa de acuerdo con los objetivos que perciba la empresa y la sociedad.

Palabras clave: Ética; contabilidad; profesión; responsabilidad; integridad.

\begin{abstract}
Successive business scandals have revealed that the professional training of accountants is not enough since current trends in the accounting profession are entangled in innumerable cases of fraud and corruption, not only in Ecuador, but throughout the Latin American region. This affects the users of financial information, understood as investors, control bodies, and the state itself, which are interested in the reasonableness of the financial statements for proper decision making. Professional ethics is a necessity that has prevailed over time, becoming a transversal axis for each individual formed with values and principles since their action affects society. For this reason, the objective of this work is to determine the ethical performance in the professional practice of the accountant and the application of corporate social responsibility, through epistemological review for a new insight of the profession. The methodology applied to achieve the objective was the bibliographic review of the epistemological approach that the accountant has determined as a complete professional, who puts the interests of the company before their own, in addition, the agreement according to the objectives undertaken by the company and society.
\end{abstract}

Keywords: Ethics; accounting; profession; responsibility; integrity.

(c) Los autores. Este artículo es publicado por la Revista Quipukamayoc, Universidad Nacional Mayor de San Marcos. Este es un artículo de acceso abierto, distribuido bajo los términos de la Licencia Creative Commons Atribución-NoComercial-Compartirlgual 4.0 Internacional.(http://creativecommons.org/licenses/by-nc-sa/4.0/), que permite el uso no comercial, distribución y reproducción en cualquier medio, siempre que la obra original sea debidamente citadas. 


\section{INTRODUCCIÓN}

Indudablemente la contabilidad ha sido primordial en el desarrollo del comercio a través de los tiempos. Las malas prácticas de esta ciencia han surgido debido a la ausencia de ética que ha llevado a la profesión a un escenario negativo que azota no solo a Ecuador, sino al mundo entero, donde se ve reflejado el interés de un individuo, sea este una persona o una entidad, menospreciando el cumplimiento para el bien común dejando a un lado el sentido del ejercicio ético profesional.

En los mercados, la aplicación de la ética deja mucho que desear, pues se presentan considerables actos que son objetos de reproche a nivel local y nacional. La ética en el Ecuador ha cobrado relevancia en los últimos años, debido a las leyes emitidas por el Estado procurando garantizar los derechos de los consumidores, los deberes y responsabilidad de los proveedores, a través de la Carta Magna de la República del Ecuador, Ley Orgánica de Defensa del Consumidor, entre otras normativas con la finalidad de prevenir y sancionar prácticas no éticas en contra del consumidor final (Ramón, 2015).

El mundo de las finanzas y de los negocios conoce al contador como el encargado de manejar correctamente la información con la finalidad de elaborar los estados financieros que apoyen en el proceso de toma de decisiones de la gerencia en la empresa, al mismo tiempo de cumplir con las disposiciones legales a las que esté implícita en su contexto (Rojas, 2014).

Actualmente, las perspectivas de la sociedad con relación al ejercicio profesional del contador y de las empresas han cambiado, el resultado de las decisiones que se toman en ella, no solo se confina a la función económica, sino que abarca un sentido social como la satisfacción de necesidades de la colectividad, de forma responsable, equitativa y mancomunada (Chumaceiro, Hernández, Yori y Ziritt, 2013).

El profesional contable debe garantizar que el papel que tienen las empresas no solo se trate de que realicen una adecuada actividad empresarial, como es la generación de trabajo, la maximización de la riqueza para la sociedad, la elaboración de informes de gestión; sino, más bien, debe estar aunado a la intervención en el desarrollo de la sociedad, entendiendo preferentemente los sectores más vulnerables (Chumaceiro et al., 2013).

La ética cobra mayor relevancia hoy en día, debido a que la sociedad está siendo afectada por innumerables casos de corrupción, que se evidencia en las organizaciones, el accionar político-público y el desenvolvimiento profesional en diversos entes. Hay un consenso en la sociedad de que se debe aplicar la ética en todos los ámbitos, porque las malas prácticas afectan a la colectividad (Ramón, 2015).

Ante lo expuesto Ramón (2015) determina que:

Los profesionales deben interiorizar que su misión es aportar su conocimiento, experiencia, compromiso y prácticas éticas para el desarrollo de la organización que paga por sus servicios, es un acto de lealtad y reciprocidad para la organización, que abriéndole sus puertas confía en que está integrando a su organización al mejor elemento, al que cubrirá sus expectativas. Sin embargo, las empresas se encuentran con frecuencia con colaboradores faltos de lealtad $y$ ética, lo cual no tarda en traducirse en cuantiosas pérdidas de dinero, y de prestigio y reputación para la empresa, porque es a través de sus colaboradores que las empresas venden su servicio a sus clientes y si ellos no tienen ética, la empresa será percibida como una empresa sin ética (p. 28).

Por tal motivo el objetivo de este trabajo de investigación es determinar la actuación ética en el ejercicio profesional del contador y la aplicación de la responsabilidad social empresarial, mediante la revisión epistemológica para una nueva percepción de la profesión.

\section{Revisión de literatura}

El hombre es un ser social por naturaleza, desde la historia de la humanidad ha buscado la asociación con los demás para protegerse y ayudarse; de tal manera que fue acogiendo los valores de su contexto, aceptando valederas algunas prácticas y descartando otras que no son admitidas socialmente.

Una característica importante a considerar del hombre que se deriva de la ética, son los valores, ya que de ninguna manera el hombre puede vivir sin ellos. Para recuperar los valores, lo realiza mediante la educación ante un mundo globalizado que ha traído cosas buenas y malas, empezando por la tecnología y, en segundo lugar, la corrupción y la falta de valores en el contexto social (Sanromán, González y Villa, 2015).

Para emprender el tema de la ética, hay que establecer su etimología, la cual Garzón y Pérez (2016) alegan:

Ética proviene -del griego ethos, carácter-alude más a la raíz del problema, pues el comportamiento es la cuna del carácter, de lo que uno hace con su vida. El ethos alude al comportamiento como la forma de forjar el carácter (p. 88).

Amaro (2015) expresa que la ética fue parte de la rama filosófica hasta el ocaso del siglo XIX, en que comenzó su 
independencia, y tiene por finalidad el estudio de la conducta moral del humano en la sociedad.

Iznaga, Parra, Hodelín y Hurtado (2017) definen a la ética como una ciencia que tiene por finalidad el estudio de la moralidad y la conducta del ser humano.

De igual manera, Betancur (2016) desde una perspectiva nodal, define a la ética como la reflexión de nuestro modelo de vida-accionar, conductas, en donde predomina la razón en el momento de decidir para comprender, razonar $\mathrm{y}$ fundamentar.

\section{Ética profesional}

La ética profesional es el conjunto de deberes y obligaciones que está presente en los profesionales, muy independiente de la labor que realizan y acatan durante el desarrollo laboral. Navia y Hirsch (2015) manifiestan que conforme transcurre el tiempo, la moral incrementa en los seres humanos, conllevando a un proceder adecuado en el campo laboral.

Ramón (2015) establece que la actuación ética de una persona no solo debe concernir al ámbito individual y colectivo, sino que debe su proceder trascendental en el ejercicio profesional, ya que tiene relación directa con la comunidad que recibe su prestación de conocimientos.

Por su parte Yurén (2013) establece que:

La ética profesional es parte de una cultura profesional que incluye un conjunto de saberes, creencias, valores y esquemas de acción que orientan las prácticas en el campo profesional. Como parte de la cultura, se transmite de una generación a otra mediante procesos de socialización y enculturación; sus elementos son más o menos compartidos por quienes se reconocen con derechos y obligaciones para ejercer la profesión; sirve de pauta de lectura a los profesionales para dar sentido a sus actividades en el contexto en el que actúan y está en la base de las prácticas profesionales $y$ de las estructuras que sostienen la profesión (p. 6).

Ramón (2015) determina que la ética profesional tiene una función y responsabilidad social, todo profesional tiene como objetivo el servir a la sociedad. El contador cumple con este propósito desde la instancia en que identifica y satisface las necesidades del mercado, el cual evoluciona y es riguroso; desarrolla habilidades y competencias requeridas por éste en el ámbito local y nacional; administra los recursos materiales, económicos y humanos; y asesora con decisiones responsables y honestas que beneficien a la empresa, lo cual promueve prácticas éticas y de responsabilidad social en pro de la consecución del desarrollo sustentable para las entidades y la sociedad.
En tal sentido, para Ramón (2015) la ética profesional tiene como función:

Hacer que el profesional adquiera conciencia ética y moral, asuma su compromiso con la profesión, ejer$z$ a sus deberes $y$ derechos protegiendo el patrimonio corporativo y social, más no su propio beneficio y con la satisfacción de que su accionar ético como profesional trasciende por el aporte que hace a la sociedad (p. 26).

Ante lo expuesto, la ética empresarial empieza a cobrar sentido en los últimos tiempos. Arredondo, De la Garza y Villa (2014) expresan que:

La ética en los negocios empieza a tomar relevancia cuando salen a la luz pública las acciones poco responsables gestadas en los centros de negocios y las empresas. Como, por ejemplo, problemas de corrupción, maltrato a los derechos humanos, violación de los derechos laborales, afectación de la calidad de vida por daños al medio ambiente, etc. Esta serie de problemas pone en el centro del debate, tanto a nivel académico como empresarial, la necesidad de adoptar y acogerse a la ética como una forma de mejorar el entorno interno y externo de los trabajadores $y$ de todos los stakeholders (p.11).

\section{Ética en el desarrollo profesional contable}

Colmenares, Da Costa y Cegarra (2014) afirman que la contabilidad es una carrera que forma egresados profesionales íntegros, basados en una formación general, con vanguardia, y competitividad en el mercado laboral, a la par que lo capacita para desarrollarse de manera ética, objetiva, científica en la elaboración de estados financieros y sus respectivos análisis para tomar decisiones de forma adecuada.

Por cuanto, González (2013) refiere que existen asociaciones de profesionales contables como la Federación Internacional de Contadores (IFAC), organización internacional que dicta normas u obligaciones éticas propias de la profesión, donde se denota la objetividad, integridad, independencia, competencia y conducta ética acorde con la buena reputación de la contabilidad.

Según De Nobrega (2019) la aplicación de la ética en el ejercicio profesional del contador ha tenido un cambio gradual y progresivo obteniendo una transformación al mismo tiempo que ha ido evolucionando la profesión y el contexto. El ejercicio profesional, nacional e internacional está basado en marcos de ética especialmente estructurados para un adecuado desenvolvimiento del contador. 
De Nobrega (2019) manifiesta los siguientes elementos comunes de los marcos de ética, en los cuales se enfatizan los siguientes componentes:

- Un marco de referencia representado básicamente por la responsabilidad, el interés de la sociedad, integridad, objetividad, independencia, cuidado de la profesión, el alcance y la naturaleza del servicio prestado.

- Además de un conjunto de reglas que rigen la profesión como la confidencialidad de la información y del usuario, competencia, conducta entre otros.

En el mismo contexto, Bastidas y Peña (2007) determinan que:

El ejercicio profesional del contador puede estar influenciado por diversos factores en relación con las exigencias de los usuarios de la información financiera, la tecnología, la globalización. Para el cual aquellos deben mostrar dentro de su misión, trabajo de calidad para la adecuada toma de decisiones de dichos usuarios, información razonable de los entes económicos o una opinión emitida al finalizar una auditoría financiera. Ante lo expuesto, se obliga al contador tomar para sí, los principios básicos de la ética como guía de su actuación. El comportamiento ético constituye un componente inseparable de la actuación profesional. Como es visto, actuar "en conciencia y a conciencia" es fundamental desde la arista de lo ideal moral. El ejercicio profesional del contador debe apegarse a este ideal moral, que, aunque es de naturaleza individual (p. 127).

El desarrollo del ejercicio profesional del contador debe estar enmarcado en estas normas que se encuentran establecidas en los códigos de ética, los cuales Ramón (2015) los determina como un instrumento formal, promulgado por las organizaciones, para exponer los principios, normativas, deberes, obligaciones que manifiestan el compromiso a cumplir con relación a sus socios, gobierno corporativo, trabajadores, medio ambiente y colectividad, con la finalidad de lograr niveles de comportamiento en materia ética y ganar reputación en el lugar donde se desarrolla.

Estos documentos sirven de guía de carácter moral que orientan la profesión. Ramón (2015) establece los siguientes apartados del código de ética que debe emplear el contador profesional para normar su actividad en el mundo laboral. En el caso ecuatoriano son:

- Ejercer su profesión con altos estándares de calidad, en conformidad con la legislación aplicable de manera profesional.
- El ejercicio profesional se normará en lo establecido en la Constitución de la República del Ecuador, Código de Comercio, Ley de Seguridad Social, Ley de Compañías, Código de Trabajo, Código Tributario, Código Civil, Código Orgánico de Procedimiento Penal, Ley Orgánica del Sistema de Contratación Pública, Código de Arbitraje y Mediación, y otras que estén inherentes a su actividad profesional.

- Acatar y cumplir con las disposiciones establecidas en el Código de ética de la entidad.

- Desenvolverse con profesionalismo, subordinando sus intereses personales a los de la organización, para generar confiabilidad.

- La labor del contador debe fundamentarse en la objetividad, dejando a un lado los prejuicios, siendo imparcialidad y evitando los conflictos de intereses.

- Debe precautelar la confidencialidad de la información financiera, evitando que sea utilizada por terceras personas.

- Independiente de los socios o directivos de la empresa, para laborar apegado a la ética o normas técnicas.

- La información generada por el contador debe reflejar la fiel naturaleza de la empresa.

- Acatar toda disposición que emitan los organismos de control, como el Servicio de Rentas Internas, Superintendencia de Compañías, Superintendencia de Bancos, Contraloría General del Estado, orden de un juez de lo civil o penal.

- Su papel es el del asesoramiento con transparencia e idoneidad a los accionistas o propietarios de la sociedad.

Los profesionales de contabilidad deben interiorizar que su propósito laboral es aportar conocimiento y competencia, comprometidos en la realización de prácticas éticas para el desarrollo del ente económico que paga por sus honorarios profesionales. Ramón (2015) afirma que:

Es un acto de lealtad y reciprocidad para la organización, que abriéndole sus puertas confía en que está integrando a su organización al mejor elemento, al que cubrirá sus expectativas. Sin embargo, las empresas se encuentran con frecuencia con colaboradores faltos de lealtad y ética, lo cual no tarda en traducirse en cuantiosas pérdidas de dinero, $y$ de prestigio y reputación para la empresa, porque es a través de sus colaboradores que las empresas venden su servicio a sus clientes y si ellos no tienen ética, la empresa será percibida como una empresa sin ética (p. 28). 


\section{Responsabilidad social empresarial}

Manuel y Andrades (2015) definen la responsabilidad social empresarial (RSE) como el compromiso por el cual las organizaciones toman la decisión de contribuir voluntariamente por una sociedad mejor y por la preservación del medio ambiente. Esto se logra alcanzar mediante la concienciación del impacto de su accionar el cual recae sobre todos los grupos de interés, y su vez manifiestan su compromiso de contribuir al desarrollo de la economía, aunado a la mejora de la calidad de vida de los trabajadores, de su familia, de la comunidad local donde desempeñan sus actividades y de la sociedad en su conjunto.

Arce, Parra, Sarmiento y Ramón (2017) definen a la RSE como:

La manera en que una empresa responde a su mercado con actuaciones éticas, en el desarrollo de sus procesos productivos. Está muy ligada a los valores establecidos por la empresa, los mismos que forman parte de su cultura organizacional. Como parte de su actuación ética, las empresas actualmente adoptan la responsabilidad social empresarial, como prácticas que demuestran a su mercado meta, que están interesadas en operar en el mercado de manera honesta, responsable, creando las condiciones laborales apropiadas para su talento humano, clientes, proveedores, protegiendo el medio ambiente, cumpliendo con sus obligaciones con el estado, mejorando la calidad de vida de las comunidades donde tienen sus operaciones y de la sociedad en general (p. 55).

De acuerdo con lo manifestado por Chumaceiro et al. se podría entender a la responsabilidad social empresarial como una normativa de la urbanidad, aplicable primordialmente al sector privado de la economía, el cual crea un elevado indicador del producto interno bruto a escala mundial, y que se le espera que cambie desde un modelo económico-empresarial a uno económico-social.

Para Sapién, Piñón y Gutiérrez (2016) la RSE —también conocida como responsabilidad social corporativa- simboliza conscientemente el compromiso integral respecto a los fines de la empresa, de manera interna como externa. Este compromiso considera las expectaciones de la economía, de la sociedad y del medio ambiente de todos sus partícipes.

La responsabilidad social corporativa no es un simple enunciado que formulen las empresas $u$ organizaciones como medio para hacerse publicidad y ganar reconocimiento en el mercado, sino que es un compromiso voluntario que asumen, para eje- cutar acciones concretas en lo económico, el medio ambiente y la colectividad, preocupándose por restituir a los grupos de interés con los que tienen relación: clientes, accionistas, directivos, proveedores, distribuidores, trabajadores, competidores, bancos, medios de comunicación, organismos de gobierno, colectividad en general; por lo que en su participación están involucradas todas las áreas de la empresa (Ramón, 2015, p. 110).

Son varias áreas en las que las empresas tienen la misión de trabajar en Responsabilidad Social Empresarial o Corporativa: tener apropiada gobernabilidad, derechos humanos, prácticas justas de operación, desarrollo de proveedores; vender productos sostenibles y seguros a los clientes; precautelar el bienestar de los trabajadores; proteger al medioambiente involucrado en el desarrollo de la comunidad; crear y participar en políticas públicas (Ramón, 2015, p. 110).

Arce et al. (2017) mencionan que la responsabilidad social empresarial conlleva la aplicación de cinco éticas relacionadas con:

1. Ética con el marketing: relacionada con el trato que se brinda y recibe de los clientes, proveedores, la competencia y publicidad responsable.

2. Ética con los trabajadores: relacionada con el cumplimiento de leyes, normas, preceptos impuestos por instituciones oficiales o estatales

3. Ética con el medioambiente: relacionada con el cumplimiento de la normativa ambiental rigente en el país donde se posesiona la empresa, y la responsabilidad que ésta implica con la comunidad.

4. Ética con el recurso humano: donde se establecen las relaciones de poder y de respeto intralaboral para una mejor convivencia que apunta a los objetivos de la empresa.

5. Ética con la comunidad: relacionada con la sociedad donde se instaura, mediante acciones de apoyo a la misma.

Barroso (2007), citando palabras de Somoggi, establece que la RSE empieza desde la propia persona, teniendo conciencia de cada quien es agente de cambio, coexistiendo un compromiso con la verdad y una percepción de que cada día es una posibilidad de mejora y desarrollo.

La premisa idónea en el planteamiento de la responsabilidad social empresarial manifestada por Duque, Cardona y Rendón (2013) es: 
Un acto de responsabilidad con la sociedad que desde la academia y las empresas se dé una oposición a las pretensiones de hacer de la RSE un concepto de moda: no en vano, el concepto ha venido fortaleciéndose a lo largo de las últimas décadas y debe ser menester de las instituciones públicas y privadas lograr acuerdos nacionales e internacionales para posibilitar la unificación de los parámetros de medición y lograr de esta manera hacer que la RSE se convierta en un concepto potente de gestión empresarial, con ética y compromiso social, político, cultural, ambiental y económico (p. 205).

Para la realización de este trabajo de investigación, se ha utilizado la metodología de investigación documental. De acuerdo con Cázares, Christen, Jaramillo, Villaseñor y Zamudio (1995) dicha metodología depende fundamentalmente de la información que se obtiene o se consulta en documentos. En este marco, se entiende por documentos, a todo material al que se puede acudir como fuente de referencia sin que se altere su naturaleza o sentido, los cuales aportan información o dan testimonio de una realidad o un acontecimiento.

La metodología empleada ha permitido el cumplimiento del objetivo de este trabajo de investigación, que es determinar la actuación ética en el ejercicio profesional del contador y la aplicación de la responsabilidad social empresarial, mediante la revisión epistemológica para una nueva percepción de la profesión.

Tomando en cuenta las políticas en materia de tributos que se han adoptado en el Ecuador, su incidencia ha favorecido en el mejoramiento de la recaudación tributaria. Zamora (2018) expresa que las políticas fomentan la disminución de la evasión de impuestos, sin enmbargo, los sujetos pasivos de la administración tributaria consideran que entre más normas, más evasión va a existir, porque las personas ya sean naturales o jurídicas siempre van a querer pagar menos.

Además, Zamora (2018) determina que:

La reducción de ingresos y el aumento de gastos es una causa de evasión determinante, en especial el aumento de gastos irreales que se da con la compra de facturas, que ha sido el determinante más preciso del periodo de estudio de la brecha evasiva determinada por la administración tributaria ente regulador de tributos en el Ecuador (p. 20).

Tal es el caso expresado por el Servicio de Rentas Internas, órgano regulador en materia tributaria, que denunció ante la Fiscalía General del Estado de Ecuador que una persona jurídica presentó en sus declaraciones comprobantes de venta de terceros por transacciones inexistentes, con facturas clonadas, de personas que indicaron que nunca mantuvieron relaciones comerciales con dicha empresa, en el año 2017.

Además, el Tribunal de Garantías Penales de Pichincha de Ecuador declaró como culpable al responsable de llevar la contabilidad de dicha empresa y lo condenó a siete años de prisión y al pago de veinte salarios básicos unificados por delito de defraudación tributaria. En cuanto a la empresa, el Tribunal Penal ordenó la extinción de la personería jurídica, que se dedicaba a la venta al por mayor de accesorios, partes y piezas de vehículos automotores, aunado a una multa de cien salarios básicos unificados equivalentes a treinta y nueve mil ochocientos dólares de los Estados Unidos de América.

Ante tal contexto, se vuelve la necesidad de exigibilidad de la ética tanto en las organizaciones económicas como en las profesionales, debido a que deben priorizar como activo principal la confianza y credibilidad. Siendo el desafío actual de los profesionales en contabilidad y de las empresas recobrar la transparencia y obtener confianza de los grupos de interés de la sociedad.

\section{CONCLUSIONES}

El comportamiento ético constituye un pilar fundamental en el ejercicio profesional, por lo cual el contador debe acoplarse a este ideal moral que, a pesar de ser de naturaleza individual, está encaminado en el bien común de la sociedad. El papel del nuevo contador está basado en su formación profesional, en el cual debe predominar la ética, ya que las empresas presentan una mayor inclinación por estos profesionales que generan una mayor utilidad dentro de la organización. La actuación del contador profesional debe ser íntegra, en la que predomine el interés de la empresa antes que los propios, además de ser una actuación encaminada con los objetivos que perciba la empresa. El contador profesional, más allá de ser ético, tiene que aglutinar esfuerzos en el desarrollo de dichos valores éticos, los cuales constituyen la moral y práctica de la profesión, por ende, queda como reflexión que los estudiantes de las diferentes Instituciones de Educación Superior, deben ser orientados en valores, en otras palabras, una educación que permita la formación integral para la consolidación en el mercado laboral. Además, toda entidad debe ejecutar una planificación de responsabilidad social que conlleve actividades de la medida y el reporte del impacto que ha generado con sus cuentas y transparencia, garantizando una mejor y sincera relación con la comunidad donde ejerce sus operaciones. Con la aplicación de la RSE, se busca fomentar una filosofía en las empresas, donde se mejore la calidad de vida de sus empleados, se estrechen mejores relaciones entre los participantes de la empresa, entiéndase como accionistas, proveedores, competencia y 
gobierno; con el objetivo de apoyar y velar por la construcción de una mejor sociedad, velando por la integridad del medio ambiente. Este enfoque al no aplicarse, podría incurrir en la quiebra y desaparición de la empresa en el mercado.

\section{REFERENCIAS BIBLIOGRÁFICAS}

Amaro, M. (2015). Ética social, profesional, profesoral y de la ciencia. MediSur, 13(6), 714-721. Recuperado el 26 de agosto de 2019, de http://www.redalyc.org/articulo.oa?id=180043167003

Arce, J., Parra, B., Sarmiento, C., \& Ramón, D. (2017). Diseño de la cultura organizacional para la estrategia de negocios. Guayaquil: Cámara Ecuatoriana del Libro. Recuperado de http://142.93.18.15:8080/jspui/handle/123456789/81

Arredondo, F., De la Garza, J., \& Villa, L. (2014). Propuesta para el diseño de un código de ética empresarial basado en la ética kantiana. Cuadernos de Administración, 30(52), 9-19. Recuperado el 16 de octubre de 2019, de http://www.redalyc.org/articulo. oa? id=225033236002

Barroso, F. (2007). Responsabilidad social empresarial: concepto y sugerencias para su aplicación en empresas constructoras. Ingeniería, 11(3), 65-72. Recuperado el 30 de agosto de 2019, de http://www.redalyc.org/articulo.oa?id $=46711307$

Bastidas, C. \& Peña, E. (2007). La ética: fundamentos de la adopción de las normas internacionales de contabilidad. Actualidad Contable Faces, 10(14), 118-128. Recuperado el 15 de octubre de 2019, de http://www. redalyc.org/articulo.oa?id=25701411

Betancur, G. (2016). La ética y la moral: paradojas del ser humano. CES Psicología, 9(1), 109-121. Recuperado el 26 de agosto de 2019, de http://www.redalyc.org/articulo.oa?id $=423545768008$

Cázares, L., Christen, M., Jaramillo, E., Villaseñor, L., \& Zamudio E. (1995). Técnicas actuales de investigación documental. México DF: Trillas. Recuperado el 20 de octubre de 2019, de http://www.academia.edu/30356880/T\%C3\%A9cnicas_actuales_de_investigaci\%C3\%B3n_documental_ Cazares_Laura

Chumaceiro, A., Hernández, J., Yori, L., \& Ziritt, G. (2013). Responsabilidad social empresarial y políticas públicas. Revista de Ciencia Social (Ve), 19(2), 309-321. Recuperado el 27 de agosto de 2019, de http://www. redalyc.org/articulo.oa?id=28026992010
Colmenares, L., Da Costa, M., y Cegarra, M. (2014). Valores éticos de los estudiantes de contaduría pública del NURR - Trujillo. Educere, 18(61), 547-556. Recuperado el 15 de septiembre de 2019, de http://www. redalyc.org/pdf/356/35639776015.pdf

De Nobrega, F. (2019). Ética y tendencias de la disciplina contable. Actualidad Contable Faces, 12(19), 19-27. Recuperado el 15 de octubre de 2019, de https://www. redalyc.org/pdf/257/25715409003.pdf

Duque, Y., Cardona, M., \& Rendón, J. (2013). Responsabilidad Social Empresarial: Teorías, índices, estándares y certificaciones. Cuadernos de administración, 29(50), 196-206. Recuperado el 16 de octubre de 2019, de http://www.redalyc.org/articulo. oa?id=225029797009

Garzón, M. \& Pérez, L. (2016). Consideraciones para el Código de tica empresarial de las empresas afiliadas a la AMAV-México. Orinoquia, 20(2), 87-101. Recuperado de http://www.redalyc.org/articulo. oa? $\mathrm{id}=89650870013$

González, E. (2013). La ética profesional, su desarrollo en valores en estudiantes de administración y contabilidad. Revista Visión Contables (11), 208-228. Recuperado de http://publicaciones.unaula.edu.co/index.php/ VisionContable/article/view/49/19

Iznaga, H., Parra, M., Hodelín, Y. \& Hurtado, G. (2017). Ética y el profesional de la información. Revista información científica, 96(1), 128-137. Recuperado de http://www.revinfcientifica.sld.cu/index.php/ric/article/view/38/1048

Manuel, J., \& Andrades J. (2015). La oferta de asignaturas de responsabilidad social corporativa y ética empresarial en las titulaciones de finanzas y contabilidad: análisis comparativo con el ámbito de la gestión de organizaciones. Revista de contabilidad, 18(1), 1-10. Recuperado de https://www.sciencedirect.com/science/ article/pii/S1138489113000289

Navia, C. \& Hirsch, A. (2015). Ética profesional en estudiantes de posgrado en dos universidades mexicanas. Revista Electrónica de Investigación Educativa, 17(1), 100-115. Recuperado de http://www.scielo.org.mx/ pdf/redie/v17n1/v17n1a7.pdf

Ramón, D. (2015). Ética profesional en Ciencias Empresariales. Machala: Universidad Técnica de Machala. Recuperado de http://repositorio.utmachala.edu.ec/ bitstream/48000/6803/1/77\%20EITICA\%20PROFESIONAL\%20EN\%20CIENCIAS\%20EMPRESARIALES.pdf 
Rojas, E. (2014). La evidencia, en los servicios especiales prestados por los Contadores Públicos Independientes. Actualidad Contables Faces, 17(28), 81-95. Recuperado de http://www.redalyc.org/pdf/257/25731098006.pdf

Sanromán, R., González, I., \& Villa, S. (2015). Los principios éticos y las obligaciones civiles. Boletín Mexicano de Derecho Comparado, XLVIII (142), 313-337. Recuperado de http://www.redalyc.org/articulo. oa?id=42737102009

Sapién, A., Piñón, L., \& Gutiérrez, M. (2016). Responsabilidad social empresarial en empresa chihuahuenses que obtuvieron el distintivo ESR 2013. Civilizar. Cien- cias Sociales y Humanas, 16(30), 223-231. Recuperado el 27 de agosto de 2019, de http://www.redalyc.org/articulo.oa?id=100246672014

Yurén, T. (2013). Ética profesional y praxis. Una revisión desde el concepto de "agencia". Perfiles educativos, 35(142), 6-14. Recuperado el 26 de agosto de 2019, de http://www.scielo.org.mx/pdf/peredu/v35n142/ v35n142a16.pdf

Zamora, Y. (2018). La evasión tributaria y su incidencia en la economía del Ecuador, 2010-2014. Quipukamayoc, 26(50), 21-29. doi: http://dx.doi.org/10.15381/quipu. v26i50.14721 